\title{
Assessment of Habitats According to Groyne Types (Using Pale Chub)
}

\author{
Joongu Kang, Hongkoo Yeo, Changsung Kim \\ Water Resource Research Department, Korea Institute of Construction Technology, Goyang, South Korea \\ Email: jgkang02@kict.re.kr, yeo917@kict.re.kr, csckim@kict.re.kr
}

Received September 6, 2012; revised October 20, 2012; accepted November 10, 2012

\begin{abstract}
A groyne zone formed by installing groynes functions as habitat or shelter for aquatic organisms during a flood. Since flow characteristics over a groyne zone are affected directly by groynes, understanding flow patterns due to shapes and types of groynes is of importance for designing groynes. In order to use groynes as an eco-friendly river structure, the ecological effects should also be considered at the design stage. In Korea, the ecological effects of groynes have rarely been examined or included for the actual design. In this study, a set of experiments were carried out to investigate flow pattern changes depending on different types of groynes. Based on the flow characteristics in the groyne zone, the scales of habitats and shelters by the groyne types were estimated. In addition, to test the applicability of a habitat evaluation model to the ecological design of groynes, River2D was used for a virtual river. For assessment of the groyne's function of ecological habitat, the suitability index of a habitat for pale chub, one of the popular fishes in Korea, was used and the habitat areas by the groyne types were analyzed. The flow changes depending on the groyne types simulated by River2D show the applicability for the simulation of an ecological habitat to the groyne design.
\end{abstract}

Keywords: Type L Groyne; Hydraulic Experiment; Recirculation Zone; River2D; Habitat Area

\section{Introduction}

As structures installed mainly at the waterfront or a riverbank, groynes protect waterfronts and riverbanks, control water passages, and secure water depth for ship transportation. Recently, it was found that the reverse flow triggered within a groyne zone and the recirculation zone in the downstream area of a river could have environmental functions such as shelters for fish during floods and habitats for a variety of aquatic organisms. Accordingly, the purposes of installing groynes have become diversified. Flows around groynes as defined by their installation are largely divided into a groyne zone where a recirculation zone is created by the separation of flow in the downstream area of a groyne and a mainstream zone where changes occur in the flow due to the protrusion of the groynes. The recirculation zone in the downstream area of groynes is not only subject to a decrease in water velocity in comparison to the mainstream area but also has functions as an ecological habitat where various flows exist.

Aquatic organisms such as fish need habitats of appropriate scales according to their species and growth conditions (limited to physical scales such as velocity of flow and water depth in this study). In Korea in particular, there are major changes between normal and flooding periods. Therefore, without appropriate shelters, aquatic organisms will be carried downstream from their original habitats. A properly designed groyne provides diverse environments as a habitat during ordinary times by forming a recirculation zone and a shelter during floods; thus, it can function to preserve the riparian ecosystem.

The first study on a recirculation zone was an experimental study dealing with a recirculation zone in the downstream area of groynes conducted by Francis, et al. [1]. Note, however, that this study did not measure the water velocity. Rajaratnam and Nwachukwu [2] attempted measuring the water velocity in a groyne zone. This study, which was conducted on two types of groynes with different lengths, measured the flow zone around groynes by dividing it into $-1 \leq \mathrm{x} / \mathrm{b} \leq 6$ and $0 \leq$ $y / b \leq 3$ (x: Length of waterway, $y$ : Vertical distance from the levee, $b$ : Length of groyne). With only two types of groynes, however, this study did not analyze the characteristics of the recirculation zone in terms of various lengths and permeability of groynes. Tingsanchali and Maheswaran [3] proposed the key characteristics of local flow fields around groynes by performing numerical analysis on a recirculation zone in the downstream area of groynes. Note, however, that the analysis applied only to impermeable groynes; the impact of groynes on flow thalweg alignment and separation zone in the downstream area was not discussed in detail. 
Changes of flow in the recirculation zone and mainstream area according to the installation of groynes vary according to the types and scales of groynes. Therefore, when designing an eco-friendly river improvement structure using groynes, it is important to consider the scales and types of groynes at the design stage to fulfill the goal of size effect (such as protection of waterfront) and the habitat improvement effect. In other words, the size effect goal and the habitat improvement goal become factors determining the shape or scale of a groyne. Under the current circumstances, however, it is difficult to quantify the habitat improvement effects.

Previous studies on quantifying the habitat improvement effects mostly used PHABSIM based on the IFIM technique. Nonetheless, the PHBSIM technique is difficult to apply to a structure such as a groyne because of its one-dimensional characteristics. A technique enabling at least two-dimensional interpretation is necessary.

This study sought to find a methodology to reflect the effects of habitat improvement on design together with the size effect goal of groynes for eco-friendly river improvement using groynes. For this, hydraulic model experiments were conducted on type I and key-type groynes. The characteristics of flow in the recirculation zone and the mainstream area were also identified. In addition, the applicability of River2D, a two-dimensional habitat assessment model, to an IFIM-based decision-making process was examined.

\section{Numerical Simulation Techniques and Hydraulic Experiment Conditions}

River2D is a two-dimensional model using a finite elements model with averaged water depth; this model enables hydraulic simulation and habitat simulation. For hydraulic simulation, simulations of flow in the upstream area and super-critical flow of natural streams and rivers are possible, including unsteady, varied simulation. In the habitat simulation using River2D, however, a macroscopic habitat simulation including energy and water quality is not included. In other words, River2D suggests the amount and size of a small-scale habitat (water depth, velocity, materials on the riverbed) for the target species of fish by simulating the relationship between the physiccal components of a river system and changes in the flow. In addition, based on the final results of River2D simulation, the weighted usable area (WUA) by incremental discharge is calculated and suggested using the instream flow incremental methodology (IFIM). Here, WUA refers to an area of the riverbed as a physical habitat weighted with the habitat suitability index by growth stage of the target species of fish.

River2D largely consists of three programs: bed, mesh, and habitat (Figure 1). River2D Bed creates a topographical file consisting of nodes and elements using the collected topographical data, and River2D_Mesh establishes a finite elements network using information on the nodes and elements based on the topographical files implemented in River2D_Bed as input data. Finally, River2D calculates the velocity and water depth based on the finite elements network established in River2D_Mesh and conducts analysis on the physical habitat by estimating the weighted usable area according to the habitat suitability index of the target species of fish.

As shown in Figure 2, a hydraulic model experiment was conducted in relation to a key-type groyne in a straight waterway measuring $2.0 \mathrm{~m}(\mathrm{~B}) \times 0.80 \mathrm{~m}(\mathrm{~h}) \times 40$ $\mathrm{m}(\mathrm{L})$; the results were compared against those of an experiment on the existing type I groyne. The experiment conditions are shown in Table 1. The experiment was performed at arm length of $0.06 \mathrm{~m}(0.06 / 0.30=0.2)$ $0.30 \mathrm{~m}(0.30 / 0.30=1.0)(\mathrm{A})$ of a key-type groyne. For purposes of comparison, however, arm length of $0.30 \mathrm{~m}$ was mainly used. As for the velocity condition, the experiment was conducted at velocity of $0.075 \mathrm{cms}-0.15$ cms.

\section{Characteristics of Flow in the Recirculation Zone on Groyne Types}

The velocity of flow on the surface in the groyne zone and around groynes was measured using the LSPIV technique. The measurements are outlined in Figure 3. In this experiment, the scale and characteristics of the recirculation zone in relation to each experiment were identified based on the LSPIV measurements. As shown

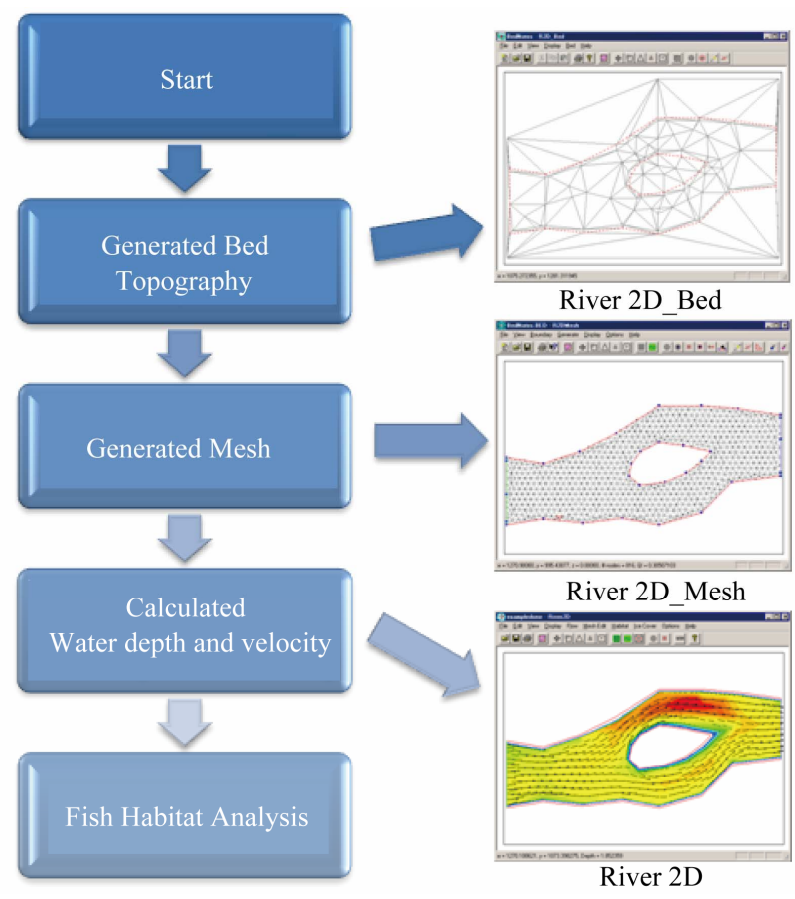

Figure 1. Modelling procedure of River2D. 

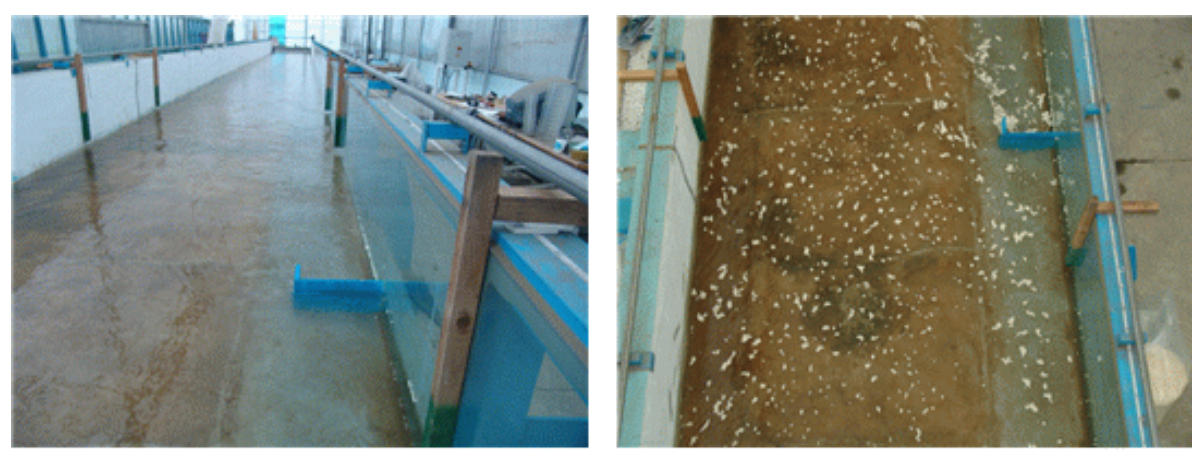

Figure 2. Experimental channel and setup.

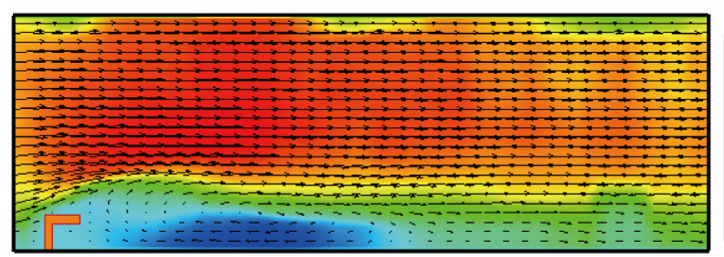

KG10V30
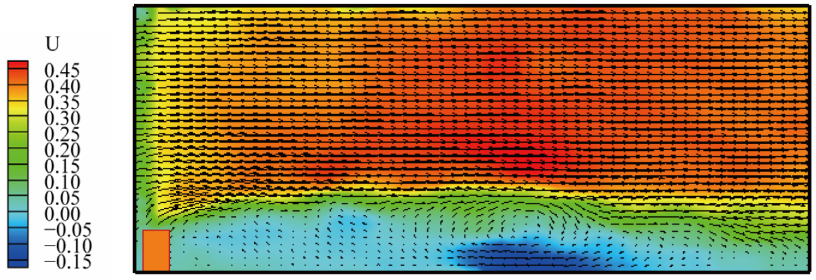

IG15V30

Figure 3. Flow fields obtained with LSPIV.

Table 1. Experimental conditions.

\begin{tabular}{|c|c|c|c|c|c|c|c|}
\hline \multirow{2}{*}{ Experimental conditions } & \multirow{2}{*}{$\begin{array}{c}\text { Groyne } \\
\text { Type }\end{array}$} & \multicolumn{6}{|c|}{ Discharge condition (cms) } \\
\hline & & 0.075 & 0.090 & 0.105 & 0.120 & 0.135 & 0.150 \\
\hline \multirow{3}{*}{$\begin{array}{c}\mathrm{H}=0.15 \mathrm{~m} \\
1 / \mathrm{B}=0.15 \mathrm{~m}\end{array}$} & IG15 & IG15V25 & IG15V30 & IG15V35 & IG15V40 & IG15V45 & IG15V50 \\
\hline & K04 & KG04V25 & KG04V30 & KG04V35 & KG04V40 & KG04V45 & KG04V50 \\
\hline & K10 & KG10V25 & KG10V30 & KG10V35 & KG10V40 & KG10V45 & KG10V50 \\
\hline \multicolumn{8}{|c|}{$\mathrm{IG} 15=(1 / \mathrm{B}=0.3 / 2 \mathrm{~m}), \mathrm{KG} 04=(\mathrm{Al} / 1=0.12 / 0.30 \mathrm{~m}), \mathrm{KG} 10=(\mathrm{Al} / 1=0.3 / 0.3 \mathrm{~m})$} \\
\hline
\end{tabular}

in Figure 4, in the case of a key-type groyne, the position of the x-direction pivot of the recirculation zone is at a distance from the position of groyne installation, equal to 5.6 times the length of the groyne. The y-direction pivot is located at a height similar to the length of the groyne. In the case of a type I groyne, the $\mathrm{x}$-direction pivot is at a distance that is 6.3 times the length of the groyne; the $y$-direction pivot is at the same position as that of the key-type groyne.

Figures 5 and $\mathbf{6}$ show the velocity distribution of cross sections and levee in relation to the ratio of groyne length $(\mathrm{L} / \mathrm{l})$. In the case of a key-type groyne, the maximum velocity was observed to be approx. 1.5 times the average velocity; within the groyne zone, the maximum velocity was found to be 0.5 times the average velocity at a distance that was six times the length of the groyne, which was near a levee. On the other hand, in the case of a type I groyne, the maximum velocity was observed to be 1.6 times the average velocity. Within the groyne zone, the maximum velocity at a distance that was 6 times the length of the groyne was found to be 0.57 times the av- erage velocity near a levee.

Under the same conditions, the maximum velocity of a key-type groyne was lower by approx. $10 \%$ than a type I groyne. As for the maximum velocity within the groyne zone, it also decreased by approx. $7 \%$.

\section{Application of an Ecological Habitat Assessment Model}

To examine the ecological habitat improvement effect, the River2D model developed at the University of Alberta in Canada was applied. As a two-dimensional model developed for actual application to rivers, River2D has a built-in flow simulation model. To examine the rationality of its own flow model, it was compared against the results of experiment and measurement.

The main objective of this study was to discuss if an ecological habitat assessment model can be applied in the design stage; therefore, only the basic applicability was examined by applying a number of assumptions. For this, the scale effect method of Ettema [4] was used. Using a scale of 1:25, a $7.5 \mathrm{~m}$-long groyne installed on a test river 


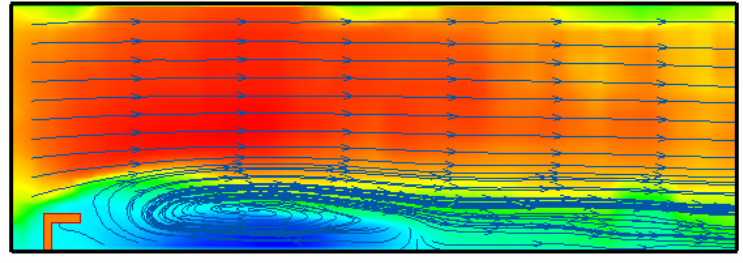

KG10V30

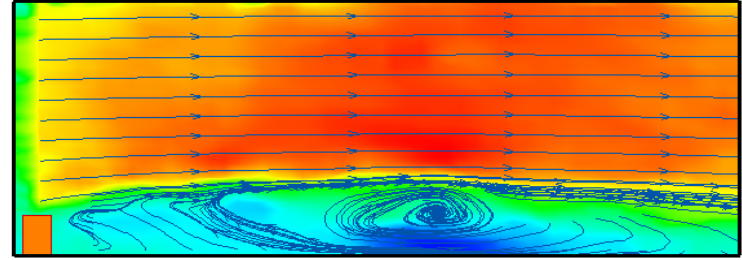

IG15V30

Figure 4. Characteristics of a recirculation zone.
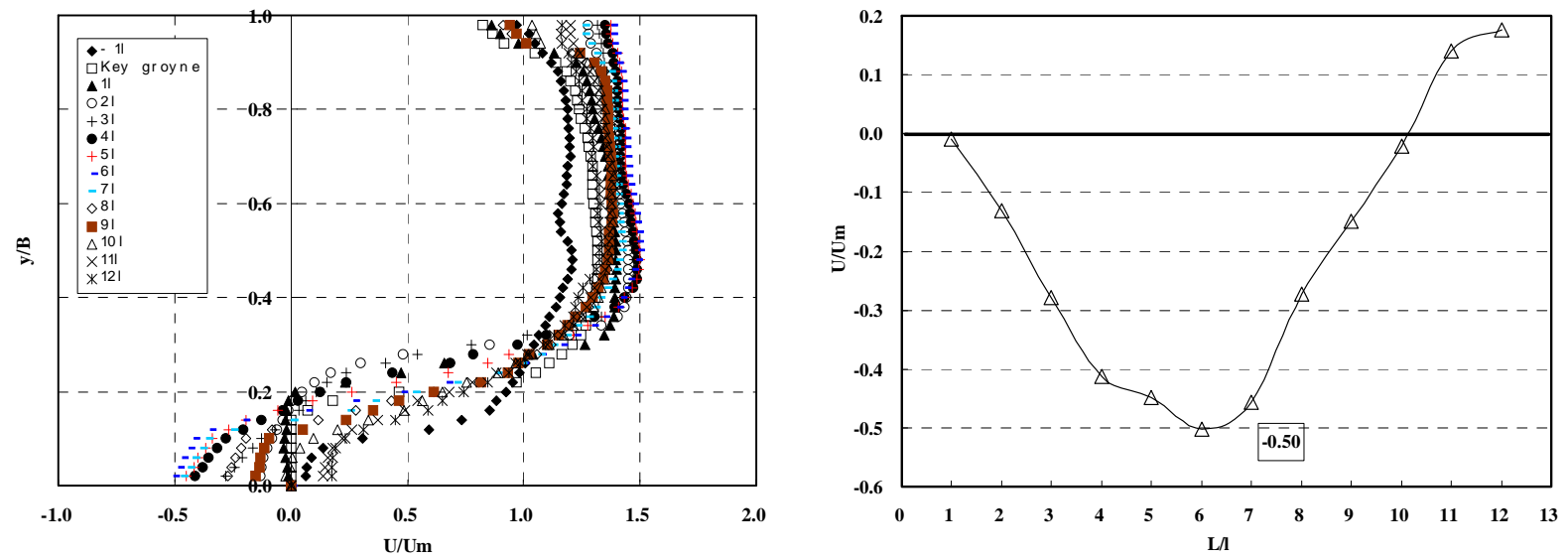

Figure 5. Velocity distribution of cross sections and levee (KG10V30).
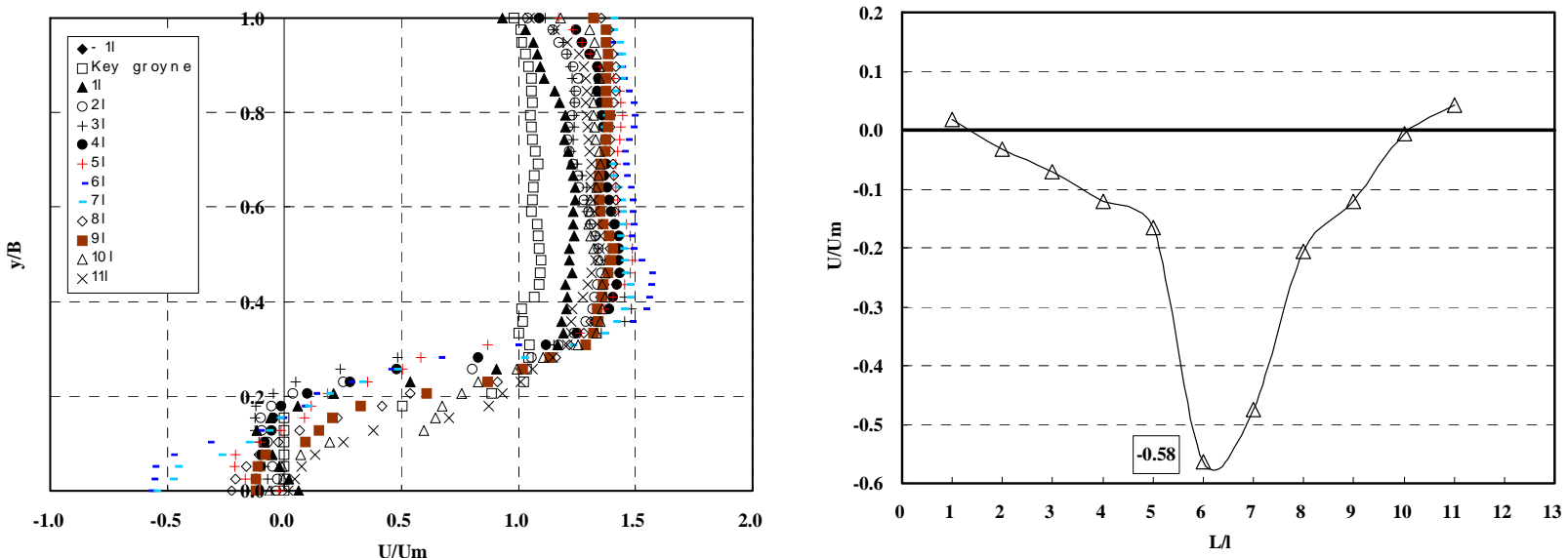

Figure 6. Velocity distribution of cross sections and levee (IG15V30).

and with width of $50 \mathrm{~m}$ was assumed. River2D was then applied (Figures 7 and 8). As for the habitat conditions for ecological habitat assessment, the conditions for pale chub used by G. H. Kim [5] were applied. As a representative fish of Korea, pale chub has the following habitat conditions (Figure 9).

Figure 10 shows the habitat areas by flow according to the groyne types. The habitat area created by the installation of groynes varied according to flow conditions, displaying a decreasing trend when flow increased. As a whole, the type I groyne had a larger area of habitat for pale chub than the type L groyne. During spawning sea- son, however, when the average velocity exceeded 1.5 $\mathrm{m} / \mathrm{s}$, the type L groyne was found to secure a larger available habitat area.

When the target flow of a virtual river is approx. 300 cms or less, the type I groyne with greater habitat effect is judged to be more appropriate. If large flows of 300 cms or more are included, however, the type L groyne would be more advantageous because it has smaller effect of velocity increase in the mainstream area and greater effect of velocity decrease around a levee of the groyne zone compared to the type I groyne. These results suggest that the type of groyne installed must be changed 


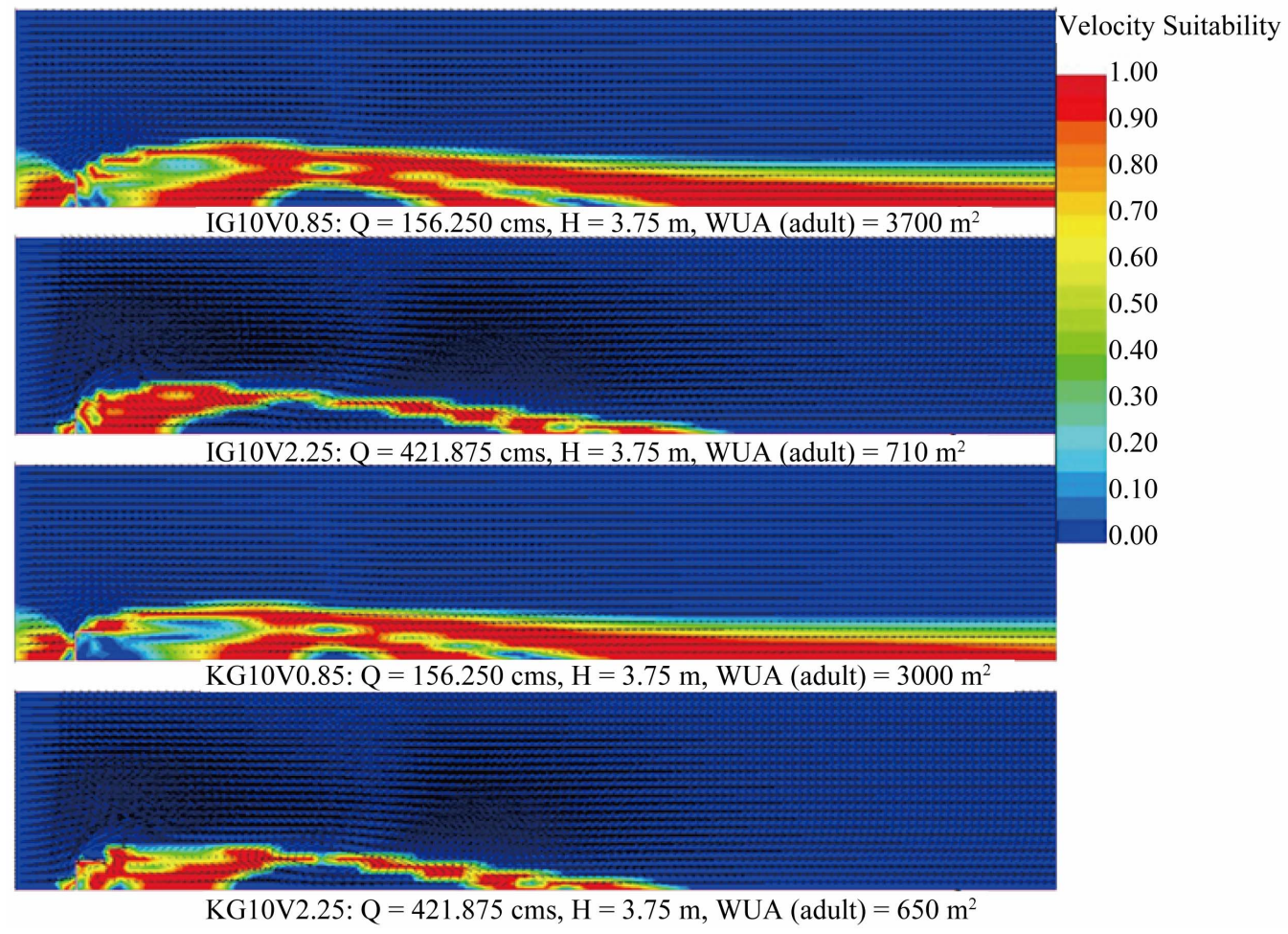

Figure 7. Weighted usable area of adult pale chub with type I groyne.

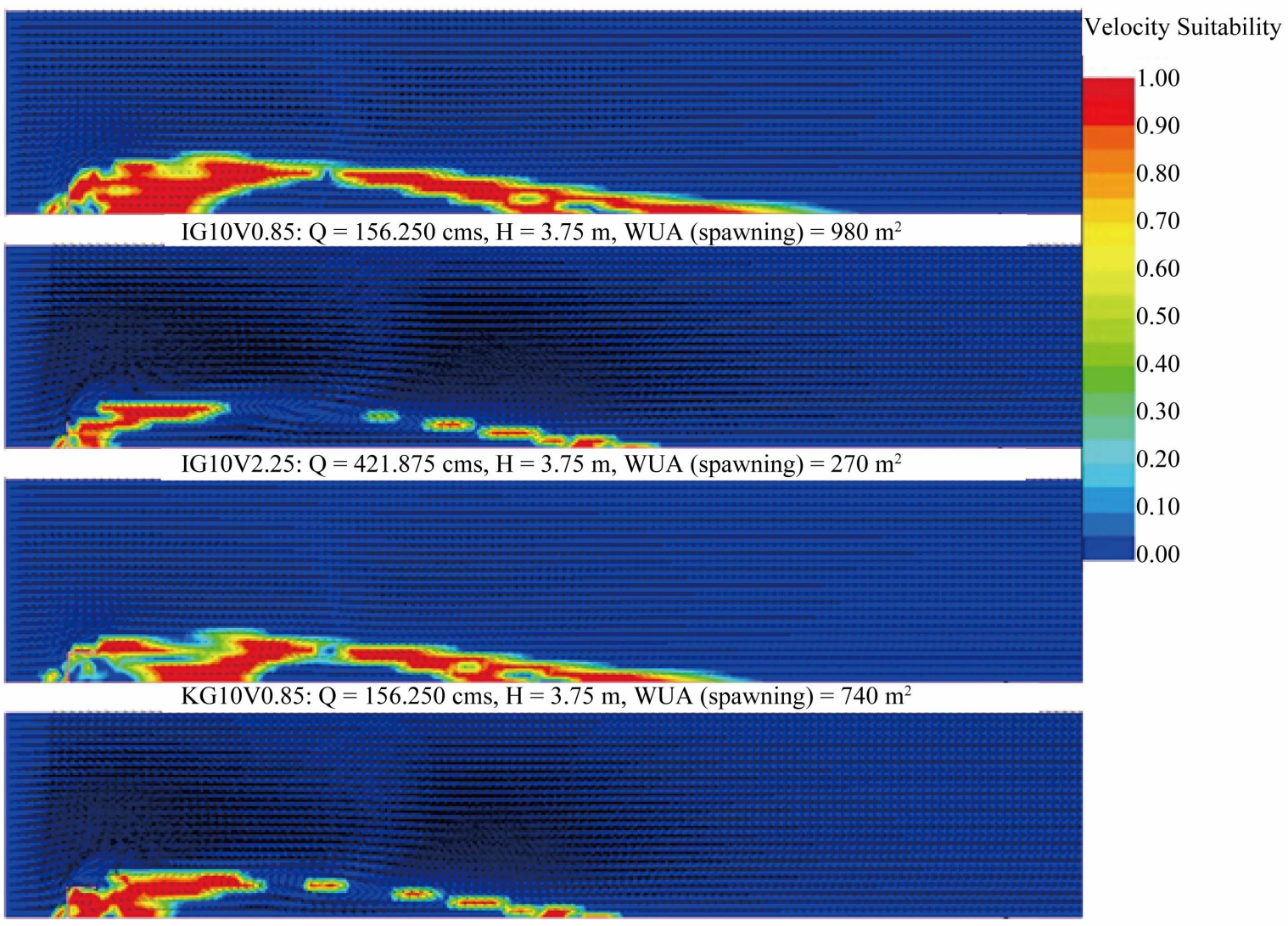

KG10V2.25: Q = 421.875 cms, H = 3.75 m, WUA (spawning) $=650 \mathrm{~m}^{2}$

Figure 8. Weighted usable area of adult pale chub with type $L$ groyne. 


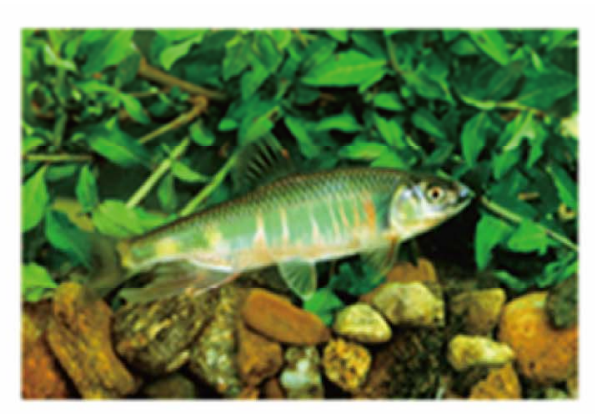

\begin{tabular}{|c|c|c|}
\hline \multicolumn{3}{|c|}{ Water depth $(\mathrm{cm})$} \\
\hline spawning & Juvenile & Adult \\
\hline $\begin{array}{c}\text { April } \sim \text { May } \\
(10 \sim 20)\end{array}$ & $\begin{array}{c}\text { Summer } \sim \text { Autumn } \\
(10 \sim 30)\end{array}$ & $\begin{array}{c}\text { Spring } \sim \text { Autumn } \\
(20 \sim 50)\end{array}$ \\
\hline \multicolumn{3}{|c|}{ Velocity $(\mathrm{cm} / \mathrm{s})$} \\
\hline spawning & Juvenile & Adult \\
\hline $10 \sim 20$ & $10 \sim 20$ & $30 \sim 60$ \\
\hline
\end{tabular}

\begin{tabular}{|c|c|c|c|c|c|c|}
\hline Pool/Riffle & Bed material & $\begin{array}{c}\text { Water } \\
\text { temperature }\end{array}$ & $\begin{array}{c}\text { DO } \\
(\mathrm{ppm})\end{array}$ & $\mathrm{pH}$ & Water quality & Spawning \\
\hline Mild riffle & Gravel, Sand & $20^{\circ} \mathrm{C}$ & 5 & 7 & 2 & Gravel, Sand \\
\hline
\end{tabular}
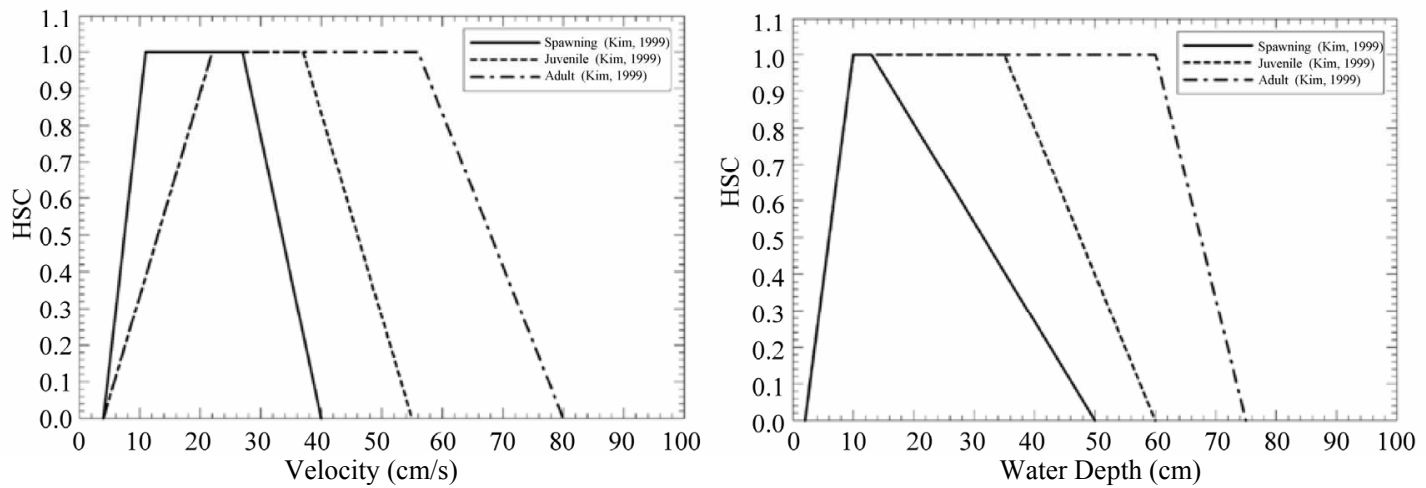

Figure 9. Habitat suitability index of pale chub (Kyuho Kim, 1999).

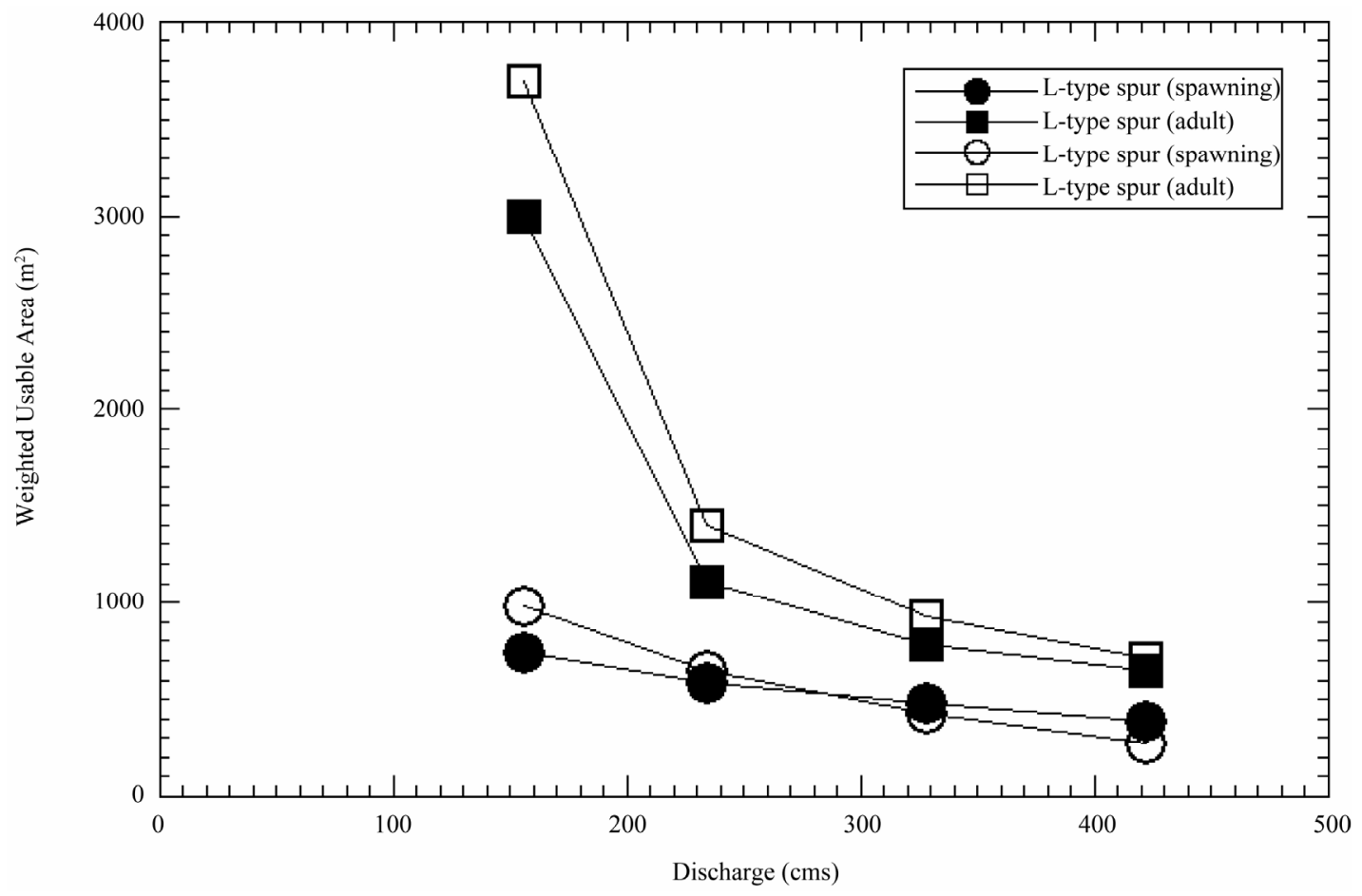

Figure 10. Weighted usable area of pale chub with discharge. 
for optimal effects according to the hydraulic impact and representative species of fish in the target river.

\section{Conclusions}

This experimental study was conducted to come up with a methodology with which to design a groyne as an ecofriendly river improvement structure by assessing its function as habitat for aquatic organisms during the flooding period. The flow characteristics of the groyne zone and mainstream area were identified in relation to type I and type L groynes. To assess the ecological habitat function of the structure, the applicability of River2D was examined.

Compared to the type I groyne, the type L groyne was subject to a smaller increase of velocity in the mainstream area and a greater effect of velocity decrease near the levee. The effect of pale chub habitat improvement was found to be greater as a whole in type I groyne than type L groyne. As for the spawning season, when the average velocity exceeded $1.5 \mathrm{~m} / \mathrm{s}$, the effect was greater with type L groyne.

The flow model of River2D produced reasonable simulation results that matched the test measurements well. Therefore, the River2D model can be used by simulating the effects of habitat improvement in advance during the stage of groyne design and reflecting the simulation results on the design of a groyne. Once the habitat suitability index is secured by identifying the ecological characteristics of aquatic organisms inhabiting rivers in Korea, it will be able to provide important data for designing groynes with ecological habitat functions.
Targeting a single species is not ideal for an ecofriendly river improvement structure aimed at improving the ecological functions. It must be designed such that a wholesome food chain formation is promoted. This study is only an experiment to assess the habitat functions of this structure for use in the design stage. Once HSI on a wide range of species is secured, however, more composite examination will be possible. For this, joint research with ecologists is urgently needed.

\section{REFERENCES}

[1] J. R. Francis, A. Pattanick and S. Wearne, "Observations of Flow Patterns around Some Simplified Groyne Structures in Channels," Technical Note No. 8, Proceedings of Institution of Civil Engineers, London, December 1968, pp. 829-846.

[2] N. Rajaratnam and B. Nwachukwu, "Flow near GroyneDike Structures," Journal of Hydraulics Division, Vol. 109, No. HY3, 1983, pp. 463-480.

[3] T. Tingsanchali and S. Maheswaran, "2D Depth-Averaged Flow Computation near Groyne," Journal of Hydraulic Engineering, Vol. 116, No. 1, 1990, pp. 71-86. doi:(ASCE)0733-9429(1990)116:1(71)

[4] R. Ettema and M. Muste, "Scale Effects in Flume Experiments on Flow around a Spur Dike in Flatbed Channel," Journal of Hydraulic Engineering, Vol. 130, No. 7, 2004, pp. 635-646. doi:(ASCE)0733-9429(2004)130:7(635)

[5] G. H. Kim, "Evaluation of Habitat Conditions and Estimation of Optimum Flow for the Freshwater Fish," Ph.D. Thesis, Yonsei Univesity, Seoul, 2000. 